\title{
Gobernanza metropolitana y producción de globalidad en Madrid y Barcelona
}

\section{Metropolitan governance and production of globality in Madrid and Barcelona}

\author{
Pedro Limón López \\ Grupo de Estudios Espacio y Poder, \\ Universidad Complutense de Madrid \\ pedro.limon@pdi.ucm.es
}

\section{NOTA BIOGRÁFICA}

Doctor en Ciencias Políticas por la Universidad Complutense de Madrid (2015), donde ha desarrollado su investigación desde 2009 vinculado especialmente al Departamento de Ciencia Política y de la Administración III (Teorías y Formas Políticas y Geografía Humana). Ha trabajado en el área de Geografía Política relacionada con procesos urbanos globales en barrios de Madrid y Barcelona.

\section{RESUMEN}

El desarrollo de políticas urbanas ha emergido como uno de los principales ejes de debate, innovación y rearticulación del territorio metropolitano en todo el mundo. Uno de los elementos principales ha sido los proyectos de gentrificación urbana, especialmente en Madrid y Barcelona, donde Hortaleza y Poblenou constituyen dos ejemplos modélicos en cuanto a transformación del espacio público de la ciudad se refiere. Desde una perspectiva basada en la Geografía Política del Derecho y en la revisión crítica de las Teorías de la Regulación, y a la luz de una investigación comparada entre los fenómenos de gentrificación de Poblenou y Hortaleza, este trabajo pretende analizar la influencia que ha tenido la praxis política institucional sobre dichos procesos de renovación y en la articulación de estos proyectos de gentrificación como elementos de producción de globalidad de Madrid y Barcelona.

\section{PALABRAS CLAVE}

Promoción urbana; gentrificación; producción de globalidad; Geografía Legal.

\begin{abstract}
In the last decades, urban policies have upsurged as one of the main axis in debates, innovation and changes around metropolitan territories. In this vein, urban gentrification processes have been one of the most importants features, especially in Madrid and Barcelona, where there have been two processes in Hortaleza and Poblenou that have upsurged as two models concerning changes around urban public spaces. From a perspective which stems from a critical review of the Regulation Theories and Legal Geography, and through a comparative research about urban renewal processes in Poblenou and Hortaleza, the aim of this work is to study how authorities affects these gentrification processes and, ultimately, in the arisen of both dynamics as key features regarding the production of globality in Madrid and Barcelona.
\end{abstract}

\section{KEYWORDS}

Urban promotion; gentrification; production of globality; Legal Geographies. 
GAPP. Nueva Época - N. 20, noviembre 2018 - ISSN: 1989-8991 - DOI: 10.24965/gapp.v0i20.10483 - [Págs. 65-81] Número monográfico - Gobernanza y políticas de desarrollo urbano: teoría y práctica

Gobernanza metropolitana y producción de globalidad en Madrid y Barcelona

Pedro Limón López

\begin{abstract}
SUMARIO
1. INTRODUCCIÓN: LA PROMOCIÓN URBANA Y RENOVACIÓN SOCIO-ESPACIAL EN MADRID Y BARCELONA. 2. DEFINICIONES, TEORÍA Y METODOLOGÍA. 2.1 CUESTIONES E HIPÓTESIS DE INVESTIGACIÓN. 2.2. DE LAS TEORÍAS DE LA REGULACIÓN Y LA PRODUCCIÓN DE GLOBALIDAD A LAS GEOGRAFÍAS LEGALES. 2.3. METODOLOGÍA. 3. (RESULTADOS) ECONOMÍA CREATIVA E INDUSTRIAS LIMPIAS EN LA PROMOCIÓN URBANA DE MADRID Y BARCELONA; 3.1. LA INTERNACIONALIZACIÓN ECONÓMICA DE MADRID Y BARCELONA. 3.2. ANÁLISIS DE LOS CASOS: POBLENOU Y HORTALEZA. 4. DISCUSIÓN: PRODUCCIÓN DE GLOBALIDAD DESDE POBLENOU Y HORTALEZA.

5. REFERENCIAS BIBLIOGRÁFICAS.
\end{abstract}

\title{
1. INTRODUCCIÓN: PROMOCIÓN URBANA Y RENOVACIÓN SOCIO-ESPACIAL EN MADRID Y BARCELONA
}

Durante las últimas décadas, el análisis de los procesos vinculados a la denominada gobernanza metropolitana ha estado ligado al surgimiento de un nuevo régimen de acumulación flexible o de acceso a los mercados (Agnew, 2005: 138-141), caracterizado por ciertos rasgos comunes que pueden observarse en los casos de Madrid y Barcelona, encarnado principalmente en la promoción urbana de ambas localidades. Desde 1992 podemos destacar numerosos cambios en ambas ciudades en relación con las transformaciones globales, a saber: se pone en marcha una estrategia estatal de branding del lugar urbano (Van Aalst y Van Melik, 2012); aparecen los fenómenos del turismo y el ocio urbanos, así como una serie de discursos incipientes sobre la cultura, el patrimonio urbano o el civismo; comienzan a regularse y proyectarse imágenes de la ciudad como representaciones globales y alusiones a la globalización (Blanco y Subirats, 2012); tienen lugar cambios en las formas de acción colectiva y movimientos sociales especialmente de las ciudades (Martí-Costa y Bonet i Martí, 2008; Blanco et al, 2011); se transforman desde la raíz las estructuras sociales e irrumpen nuevas políticas urbanas que emergen como uno de los instrumentos principales de la gobernanza metropolitana, especialmente a partir de la consolidación de programas de gentrificación y renovación urbana (Dot Jutgla et al, 2010; Muñoz Carrera, 2011).

Esto, en Madrid y Barcelona, queda encarnado en los casos de Hortaleza y Poblenou, donde se reproducen prácticamente punto por punto todos estos cambios generados a nivel metropolitano global, total o parcialmente, pasando de ser espacios significativos a nivel cotidiano y popular a convertirse en nodos del branding urbano, donde el ocio y el turismo (vacacional y de congresos) aparecen en ambos escenarios a instancias de sus transformaciones urbanísticas y programas políticos (Martín Roda, 1999; Gea Ortigas, 2002; AAVV, 2004; AAVV, 2007a, 2007b; Barrado Timón, 2010; Borja, 2005).

Dentro de una forma de promoción urbana en la que los eventos internacionales y los fenómenos de gentrificación tienen un peso determinante en los mecanismos de globalización de las ciudades, las formas de reestructuración urbana en Hortaleza y Poblenou están determinadas por la actuación institucional y la praxis normativa en el espacio público de Madrid y Barcelona, por lo cual este trabajo analiza la reestructuración de ambas localidades en clave global desde una perspectiva geográfico-política del Derecho.

En el próximo apartado esbozaré las líneas teóricas sobre las que se desarrolla un análisis crítico de los procesos de gentrificación, desde una perspectiva que incluye aportaciones de las Teorías de la Regulación, la conceptualización de la producción de globalidad y el enfoque particular de la Geografía Política del Derecho.

Posteriormente, se utilizan los resultados extraídos de una investigación comparada acerca de dos fenómenos de gentrificación consolidados en Hortaleza (Madrid) y Poblenou (Barcelona), analizando el impacto que la actuación institucional ha tenido en dichos procesos y en las proyecciones generadas a través de los mismos. Finalmente, se discuten los resultados de dicho análisis y la pertinencia del enfoque aquí adoptado para estudiar los procesos políticos urbanos desde una perspectiva más amplia de gobernanza metropolitana.

\section{DEFINICIONES, TEORÍA Y METODOLOGÍA}

\subsection{Cuestiones e hipótesis de investigación}

Bajo el paradigma de la promoción urbana y bajo el soporte de múltiples políticas públicas comunitarias, los fenómenos de renovación y gentrificación urbana en se han convertido en ejes de la reestructuración territorial del espacio público de las ciudades y, de forma simultánea, en elementos centrales dentro de los 
GAPP. Nueva Época - N. 20, noviembre 2018 - ISSN: 1989-8991 - DOI: 10.24965/gapp.v0i20.10483 - [Págs. 65-81] Número monográfico - Gobernanza y políticas de desarrollo urbano: teoría y práctica

Gobernanza metropolitana y producción de globalidad en Madrid y Barcelona

Pedro Limón López

procesos de globalización urbana. En este sentido, los fenómenos de gentrificación podrían definirse como aquellos procesos por los cuales un espacio urbano en particular, anteriormente despoblado, socialmente erosionado o sin apenas relevancia en las inversiones en la ciudad y configuración espacial, emerge como un espacio con impacto relevante en las prácticas y discursos urbanos, así como en las inversiones desarrolladas de cara a la atracción de consumo, incluyendo la mejora de los entornos físicos o la creación de espacios de ocio (Harvey, 2007: 377; Smith, 1996: 38-42). Además, la gentrificación también es una gran narrativa de alcance global que ha influido en las prácticas e imaginarios políticos y en la forma de mirar el cambio social a gran escala, y no sólo fenómenos urbanísticos concretos. En este sentido y frente al excesivo protagonismo de las visiones económicas o aun economicistas de la misma, se sostiene que la gentrificación es un proceso político en sentido amplio, toda vez que no sólo se articula a través de diferentes intereses por los recursos y las relaciones sociales de poder, redefiniendo el acceso a dichos recursos. Asimismo, entraña reestructuraciones sociales que afectan a la composición, asentamiento e interacción de los grupos sociales; genera nuevas centralidades espaciales de relaciones sociales y acceso a diferentes recursos; antecede o se apoyan en políticas públicas urbanas que influyen, modifican o reconstruyen el espacio urbanístico del territorio sobre el que se asientan (barrio o distrito) y sus significados políticos. Finalmente y a nivel de significados, la gentrificación constituye un proceso político porque es percibida, contestada y representada a nivel popular como algo político.

En el caso aquí analizado y a diferencia de algunas perspectivas economicistas del análisis urbano que atribuyen la configuración de determinados fenómenos de renovación urbana a la mera interacción de factores socioeconómicos, sostengo que la actuación institucional ha sido clave en la consolidación de los procesos de gentrificación en Poblenou y en Hortaleza. La hipótesis principal es que ambos fenómenos de gentrificación han vinculado dichos lugares a la producción de globalidad de Madrid y Barcelona, transformándose en representaciones globales y globalizadoras de sendas ciudades, fundamentalmente a través de proyectos e iniciativas de reestructuración urbana ligados a las denominada economía creativa y del conocimiento.

Recapitulando: tanto Hortaleza como Poblenou constituyen especificidades del modo en que se vertebran procesos de producción de globalidad urbana desde Madrid y Barcelona, así como casos ideales dentro de los conflictos socio-políticos en fenómenos de gentrificación o en las nuevas políticas urbanas que reconfiguran el territorio urbano a través de iniciativas ligadas a economías creativas y del conocimiento.

\subsection{De las Teorías de la Regulación y la producción de globalidad a las geografías legales}

Desde la perspectiva aquí propuesta, los procesos de renovación y gentrificación de la ciudad se entrelazan en la producción de globalidad urbana con diferente alcance: por una parte, establecen proyecciones particulares y representaciones sobre la imaginación geográfica global en la que turismo, espacios renovados y restauración paisajística aparecen en el centro de tales imaginarios. Por otra, difunden nuevos espacios públicos urbanos vinculados a la gentrificación que, a su vez, se han visto influidos por los procesos de integración regional. Finalmente y vinculado a ambas dinámicas, se estructuran transformaciones normativas que producen nuevas formas de espacialidad urbana y reconfiguración territorial, estableciéndose nexos entre la reestructuración productiva, la actuación política llevada a cabo desde las instituciones públicas -especialmente a través de la actuación jurídica y normativa- la producción de globalidad y los cambios en la planificación territorial local.

Con el fin de analizar los procesos anteriormente descritos desde una perspectiva que integre las transformaciones urbanas a variables de acumulación económica y a la praxis política ejercida desde las instituciones, se propone la aplicación y revisión teórica de algunos de los elementos de las líneas de investigación conocidas como Teorías de la Regulación. A grandes rasgos, el argumento principal de esta corriente teórica es que existiría un par conceptual formado por el régimen de acumulación, por una parte, y el modo de regulación, por otra. El primero se refiere a «un conjunto de relaciones macroeconómicas que permiten la acumulación expansiva de capital sin que las inestabilidades inherentes al sistema lo destruya (...), [mientras que] por modo de regulación entendemos el conjunto de interacciones entre instituciones sociales, políticas, normas culturales, códigos morales y prácticas que garantizan el régimen de acumulación e interactúan con el mismo» (Painter, 1998: 277-278). Lo esencial es que dentro de un régimen de acumulación las tensiones mediadas o recreadas por el modo de regulación nunca se resuelven, sino que se desplazan hacia otros espacios mediadores o que redefinen el conflicto: el cambio en el régimen de acumulación tiene, desde esta perspectiva, su expresión en los modos de regulación que asegurarían o garantizarían el primero. 
Desde esta perspectiva, existe un cambio en el regimen de acumulación global estrechamente ligada al modo de regulación metropolitano (Judge et al, 1998), según el cual se habría impulsado el denominado paradigma de la promoción urbana, que no es sino una estrategia de atracción de capital internacional y trabajo cualificado a determinados lugares que son promocionados globalmente a través de megaeventos espectaculares o acontecimientos de renombre internacional, como espectáculos deportivos (mundiales de fútbol o juegos olímpicos), diferentes tipos de fórum, festivales o ferias (Harvey, 2007; Smith, 2008). Esta promoción es urbana en la medida en que suele hacerse para favorecer determinadas ciudades, aunándose también con un proceso de reindustrialización donde la terciarización y la producción cultural (ocio, turismo, etc.) tienen un peso fundamental (Hall, 1984; Hall y Pain, 2006). Al mismo tiempo, estos eventos están relacionados con cambios en las formas de producción o retórica cultural, múltiples referentes e imaginarios procedentes de la Unión Europea o indicadores y formas de clasificación jerárquica de ciudades a escala global. Finalmente, los procesos de promoción urbana se han apoyado sobre políticas de renovación, marketing y fenómenos de creación de imágenes-ciudad a partir de procesos turísticos y de renovación urbana, haciendo de las representaciones e imaginarios de cambio urbano vinculados a la gentrificación un elemento central en los procesos de globalización.

Por otro lado, las Teorías de la Regulación son responsables en buena medida del establecimiento de tipologías y jerarquías de ciudades atendiendo a su globalidad en función de diferentes criterios, fundamentalmente económicos, que han situado en el escaparate académico múltiples espacios urbanos a escala mundial. Si bien el uso de indicadores económicos, demográficos o de dirección política es perfectamente pertinente en el análisis de procesos globales, desde la óptica aquí escogida no se trataría tanto de saber si estos espacios urbanos son o no son ciudades globales, o en qué nivel estarían dentro de las clasificaciones de este tipo de metrópolis, sino más bien analizar los procesos productores de globalización que, desarrollándose desde o sobre espacios urbanos particulares a partir de procesos de interacción social y política conflictiva, terminan generando un tipo de imaginario para la ciudad en su conjunto que atañe a las representaciones globales de esa ciudad y a la interacción entre escalas de representación política.

Es decir, estudiar cómo se desarrolla la producción de globalidad desde espacios concretos y particulares hacia imaginarios espaciales más amplios, incluyendo esos procesos urbanos recientes dentro de las estructuras anteriores que permean los espacios de la ciudad (Marcuse y Van Kempen, 2000). La producción de globalidad como concepto teórico es una alternativa que enfatiza en cómo se construyen determinadas representaciones sociales y políticas que transforman la imaginación geográfica global en relación con los espacios urbanos. Este concepto hace alusión a la generación de imágenes o representaciones de determinadas localidades que implican la inclusión (total o parcial) de esa localidad o de determinados lugares en esa visión de totalidad o de conjunto del mundo vinculada a los procesos de globalización y que, a su vez, suponen la resignificación, contestación o negociación de tales imaginarios globales desde dichos procesos particulares. Asimismo, la producción de globalidad es una herramienta teórica que permite poner de manifiesto las ambigüedades producidas en la configuración de imaginarios globales urbanos, así como la naturaleza contextualizada, localizada, de esos mismos elementos productores de globalidad. Por supuesto, eso no significa que se descarten sin más dichos criterios urbanos en la articulación y aplicación del concepto de producción de globalidad, aunque en estos tengan mucha influencia dichos indicadores económicos no por lo que demuestran, sino porque tales indicadores ejercen mucha influencia sobre la actuación institucional en múltiples ciudades (Marcuse y Van Kempen, 2000: 272). Además, la producción de globalidad tiene lugar a menudo a través de acontecimientos internacionales de diferente índole, pero también mediante nuevas formas de producción, entre las que se incluye la producción del conocimiento o las representaciones ofrecidas por los expertos o a través de múltiples políticas públicas, donde la actuación instucional es central para la reestructuración del espacio público urbano.

Por ello, se propone la aplicación de la Geografía política del derecho en el examen de dichos procesos de reestructuración urbana. En la medida en que las Teorías de la Regulación se refieren a «las estructuras institucionales que soportan y estabilizan un regimen de acumulación dado, tanto las reglas formales impuestas por las instituciones así como las normas y expectativas informales que emergen de patrones culturales y sociales» (Fainstein et al, 2003: 2), han profundizado en las consecuencias sociales y políticas que tienen tales regulaciones, así como en las implicaciones de la agencia institucional sobre los procesos globales.

En ese aspecto, es central el papel desempeñado por las administraciones sobre la reestructuración del espacio urbano a través de la producción normativa. En este sentido, la actuación institucional y la concepción geográfica contenida en la ley son centrales para comprender la imaginación geográfica sobre el espacio público en la ciudad y las formas de control sobre el mismo. 
GAPP. Nueva Época - N. 20, noviembre 2018 - ISSN: 1989-8991 - DOI: 10.24965/gapp.v0i20.10483 - [Págs. 65-81]

Número monográfico - Gobernanza y políticas de desarrollo urbano: teoría y práctica

Gobernanza metropolitana y producción de globalidad en Madrid y Barcelona

Pedro Limón López

Influida por la Sociología jurídica, la geografía legal crítica surge como una corriente dentro de la Geografía política, dirigiéndose hacia los nexos existentes entre el espacio y la ley (Blomley, 2008: 156), fundamentalmente a los «diferentes espacios y localizaciones; reglas y expectativas que regulan dichos espacios; y las implicaciones de esas distintas espacialidades sobre las cualidades de los actores públicos» (Staeheli, 2010: 71). Frente a visiones que consideran la ley y el espacio como entes pre-políticos y separados, esta perspectiva examina cómo «el espacio modifica o reforma los efectos de la ley, y simultáneamente cómo la ley da forma a las relaciones espaciales» (Martin et al, 2010: 177). Así, se centra en tres cuestiones principales: cómo la acción e interpretación legal es capaz de producir distintos espacios, en la naturaleza situada de la interpretación legal, y en el estudio de las demandas geográficas y representaciones contenidas en el discurso legal, especialmente las que cuestionan o reproducen la congelación de la imaginación política a través de la ley.

Asimismo, constituye una metodología transversal a otras, instando a un estudio multidisciplinar alrededor de diversos temas de análisis. Así, pueden destacarse propuestas que han enfatizado en la influencia de las instituciones en la reasignación de los derechos de propiedad establecidos en los fallos judiciales (Coase, 1960); hay estudios relevantes que tienen en cuenta los desplazamientos espaciales relacionados con las políticas de propiedad privada y del mercado de bienes raíces (Blomley, 2003, 2004); los efectos socio-espaciales derivados de la legislación urbanística en procesos de gentrificación y renovación urbana (Lees et al, 2008); la influencia que tiene la representación política sobre la imaginación cartográfica de los procesos sociales y políticos (Forest, 2001); el desarrollo de ordenanzas y políticas públicas en la escala local para reprimir y sancionar prácticas sociales informales, como la mendicidad o el menudeo (Dangschat, 2009; Mitchell y Heynen, 2009; Herbert, 2010; Staeheli, 2010); o finalmente, la negociación producida entre el ámbito institucional, los discursos públicos y las prácticas cotidianas en la definición de los espacios públicos y políticos (Mitchell y Staeheli, 2005; Lindón, 2007).

Finalmente, la normativa supone en muchas ocasiones una posibilidad de desarrollo de otros fenómenos socio-políticos, además de erigirse como una de las pruebas empiricas de que tales procesos se han diseñado, aprobado y desarrollado en contextos espacio-temporales específicos y con unos fines determinados. En términos de la facticidad y validez de las investigaciones, se trata de una subdisciplina con un marcado carácter empírico no sólo por su enfoque -que también, confundiéndose en muchas ocasiones con el mero positivismo descriptivo-, sino por la cantidad de material existente disponible para el análisis y la profundización de los estudios en cuestión. Al perseguirse el análisis de patrones espaciales de comportamientos o prácticas políticas institucionalmente regladas y registradas, el estudio de los mecanismos de producción de la ordenación socio-espacial de estos procesos dispone de una amplia base de datos y puede responder con una solidez empírica considerable, especialmente dentro de la Ciencia Política.

Evidentemente, la actuación institucional a través de la normativa no es la única producción de representaciones globales del espacio urbano, puesto que existen mecanismos de contestación de estas formas de imaginación de la ciudad, como pueden ser fenómenos de acción colectiva o prácticas cotidianas desarrolladas en los barrios analizados. No obstante, debido a que no es posible recabar todas las actuaciones políticas desarrolladas en dos procesos tan amplios y a causa de la importancia de la praxis política ejercida desde las instituciones por su influencia, alcance y consolidación en la reestructuración urbana de ambos barrios durante más de dos décadas, el presente artículo se centra en las perspectivas institucionales, aun a riesgo de eludir otras formas de imaginar y cartografiar la ciudad.

\subsection{Metodología}

Con el fin de responder a las cuestiones planteadas desde la óptica esbozada, la investigación sigue una metodología de estudio de caso instrumental o extendido, en la que se consideran las particularidades del mismo dentro de un análisis sistemático de procesos sociales más amplios que re-formulan estas situaciones concretas y, a su vez, permite establecer un análisis en profundidad del contexto así como ciertas generalizaciones dentro de la teoría social (Burawoy, 1991; Ragin y Becker, 1992; Stake, 1998; Denzin y Lincoln, 2005: 450). En este caso, se parte del estudio comparativo de dos procesos estudiados de forma exhaustiva a lo largo de dos décadas en Barcelona y Madrid, como son, respectivamente, Poblenou y Hortaleza, análisis enmarcado en una investigación doctoral realizada entre 2010 y 2015, con las actualizaciones normativas y documentales pertinentes.

Las fuentes de información utilizadas para este trabajo han sido de forma principal el análisis de fuentes políticas primarias, a saber: leyes estatales relativas a regulación, espacios o planificación urbanística; legislación y normativa autonómica en materia similar; planes de ordenación urbanística y normativa municipal 
acerca de la regulación de los procesos sociales y políticos señalados anteriormente desde 1992; sentencias judiciales vinculadas a dichas normativas; programas políticos de los partidos en materia metropolitana, urbana global y local, e implantación, organización y actividades a escala de barrio y de distrito; manifiestos y comunicados procedentes de asambleas populares, asociaciones y movimientos sociales; cartografía institucional de la ciudad y sus diferentes espacios oficiales. Además, de forma secundaria, se ha procedido a la revisión de fuentes estadísticas y el contraste de los datos recabados a partir de entrevistas semiestructuradas realizadas a actores relevantes en los procesos de gentrificación analizados.

Así, siguiendo el análisis histórico de contenidos, se observan las prácticas de producción política generadas a partir del discurso legal (Chouliaraki y Fairclough, 1999: 23), establecidas por las administraciones competentes en material de renovación urbana en torno a los ejemplos propuestos en la última década, permitiendo establecer recurrencias y fracturas dentro del análisis comparativo sugerido.

\section{ECONOMÍA CREATIVA E INDUSTRIAS LIMPIAS EN LA PROMOCIÓN URBANA DE MADRID Y BARCELONA}

\subsection{La internacionalización económica de Madrid y Barcelona}

Analizando la internacionalización de la economía española, el incremento exponencial en los intercambios trans-nacionales y apertura económica desde la entrada en la Unión Europea en 1986 ha supuesto un impacto creciente desde los años noventa sobre la inversión extranjera directa, el comercio, los flujos migratorios o la inversión tecnológica (Pareja-Eastway et al, 2009: 24). Desde los años 90 esta reestructuración económica se centralizó en los servicios vinculados al ocio y al turismo especialmente, en la industria de altas tecnologías o en la combinación un tanto laxa denominada economías creativas y del conocimiento (Muñoz, 2008, 2010; Navarro Yáñez, 2012). Entre las primeras se establecerían formas de producción como la arquitectura, la producción audiovisual o artística, el diseño o la publicidad, mientras en la segunda se encuadrarían elementos como la I+D+i, las tecnologías de información y comunicación, los servicios financieros o la asesoría legal (Pareja-Eastway et al, 2009: 35).

En términos prácticos, ello implicó una concentración de capital empresarial en Madrid y en Barcelona de un volumen considerable y, merced a la diferencia del mismo, la diferenciación entre una y otra ciudad por sector, actividad y tradición, lo que nos lleva al paradigma de la promoción urbana. Esta promoción es una estrategia mediante la cual las ciudades se sitúan en el centro de la planificación institucional dentro de una nueva división internacional del trabajo en la que se producen formas de marketing internacional vinculadas a la ciudad, introduciendo códigos específicos en función del sector productivo y provocando ventajas regionales o globales. De esta forma, mientras en Barcelona se produce una especialización en turismo vacacional y en la regeneración de la industria avanzada, así como en economías creativas o el patrimonio, en Madrid se deriva hacia el turismo de ferias y congresos, los servicios financieros o las funciones de control y comando. De este modo, Madrid se considera una metropolis de rango internacional especializada en actividades de servicios (Zárate Martín y Rubio Benito, 2010: 179), está considerada una plaza financiera esencial (Sánchez Moral et al, 2008: 36) y la importancia del sector servicios se acerca al $80 \%$ del PIB y de la fuerza de trabajo en la region (Muñoz Carrera, 2011: 4).

Vinculada a esta gestión de los recursos materiales, se encuentra la producción de recursos simbólicos en los ámbitos urbanos, erigiendo al Estado (o las instituciones administrativas) como agente del mercado, pasando de tener un rol redistributive hacia dentro a convertirse en un actor que incluye sus propias ciudades en un escaparate global con el fin de atraer inversion, trabajo, flujos migratorios o formas de representaciones, pujando en un sistema de competencia global. En este sentido, tanto en Madrid como en Barcelona, el Estado ha venido actuando a todos los niveles de manera constante, especialmente desde la transformación urbana generada por los eventos internacionales de 1992, que constituyeron otros ejemplos determinantes en la renovación de la ciudad, como fueron los acontecimientos de los Juegos olímpicos de Barcelona y el reconocimiento de Madrid como Ciudad Europea de la Cultura (Gil de Arriba, 2010).

\subsection{Análisis de los casos: Poblenou y Hortaleza}

Atendiendo a la perspectiva histórica, ambos barrios son dos espacios de tradición y memoria histórica de lucha vecinal y de modelos de articulación del conflicto y transformación del mismo, desde los viejos 
GAPP. Nueva Época - N. 20, noviembre 2018 - ISSN: 1989-8991 - DOI: 10.24965/gapp.v0i20.10483 - [Págs. 65-81] Número monográfico - Gobernanza y políticas de desarrollo urbano: teoría y práctica

Gobernanza metropolitana y producción de globalidad en Madrid y Barcelona

conflictos de clase a las nuevas formas de contestación identitaria y territorial (Checa Artasu, 2008; Tienda Burgos et al, 2009). Además, tienen unos antecedentes similares en términos de independencia territorial del municipio urbano hasta su integración posterior, con consecuencias en sus relaciones funcionales con la ciudad y los procesos de identificación colectiva, así como en las formas de reestructuración urbana vinculada a las dinámicas de gentrificación experimentadas, siendo dos lugares paradigmáticos a escala estatal en este aspecto (Observatorio Económico, 2005, 2011; FAVB, 2008, 2010, 2011, 2013; Muñoz Carrera, 2011; Ayuntamiento de Madrid, 2012b; Ajuntament de Barcelona, 2012b; Aguilera, 2013; Recio, 2013). En relación con los procesos urbanos globales, ambos sitios constituyen nodos de articulación del marketing urbano, y en lugares fundamentales de ocio, turismo y reestructuración económica. En términos de polarización social, se produce un contraste entre los barrios del distrito, generándose dinámicas de gentrificación al interior de los mismos que fragmentan la estructura histórica anterior, como sucede en Barcelona con Poblenou o el Besòs frente a Diagonal Mar o en Madrid con Pinar del Rey y Canillas frente a la zona de IFEMA, Valdefuentes o el parque de Valdebebas. Finalmente, se trata de dos espacios plenamente protagonistas en el patrimonio cultural de la ciudad, existiendo convergencias en la defensa de los usos necesarios del patrimonio arquitectónico e industrial (en Poblenou) o el vegetal, fundamentalmente en defensa de los valores medioambientales o de zonas verdes para los barrios populares (FAVB, 2010: 270).

Dentro de los procesos de gentrificación desarrollados en ambos lugares, aquí se analiza el impacto que han tenido el proyecto 22@ en el caso de Poblenou en Barcelona y la Gran Vía de Hortaleza, en el caso de Hortaleza en Madrid.

FIGURA 1. MAPA DE BARCELONA CON LA DIVISIÓN POR DISTRITOS

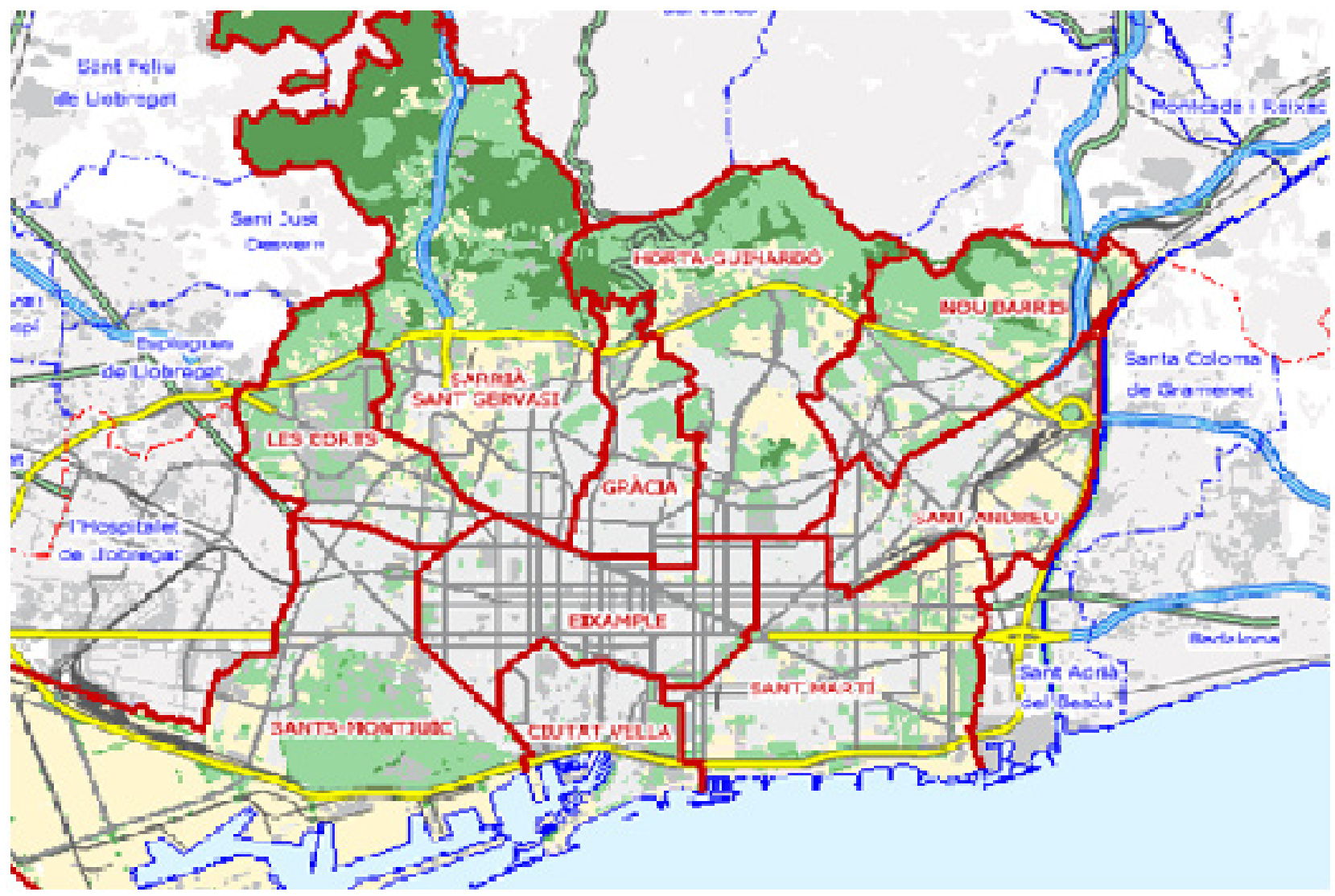

Fuente: Ayuntamiento de Barcelona.

Poblenou es un barrio administrativo del distrito barcelonés de Sant Martí, situado al sureste del municipio de Barcelona y colindante con el mar, si bien la referencia en adelante a Poblenou difiere significativamente de su consideración administrativa. El distrito de Sant Martí cuenta con las divisiones administrativas 
GAPP. Nueva Época - N. 20, noviembre 2018 - ISSN: 1989-8991 - DOI: 10.24965/gapp.v0i20.10483 - [Págs. 65-81] Número monográfico - Gobernanza y políticas de desarrollo urbano: teoría y práctica

Gobernanza metropolitana y producción de globalidad en Madrid y Barcelona

Pedro Limón López

barriales de Poblenou, Camp de I'Arpa del Clot, El Clot, el Parc i la Llacuna del Poblenou, la Vila Olímpica del Poblenou, Diagonal Mar i el Front Maritim del Poblenou, el Besòs y el Maresme, Provençals del Poblenou, Sant Martí de Provençals y La Verneda i la Pau ${ }^{1}$. Aunque podría pensarse que la división administrativa es suficiente para establecer el objeto aquí expuesto, lo fundamental son las reestructuraciones realizadas también en el área que lo rodea, por lo cual en lo sucesivo me referiré a Poblenou como un área socioeconómica e histórica que alberga la división administrativa de Poblenou, el Parc i la Llacuna de Poblenou, la Vila Olímpica de Poblenou, Diagonal Mar i el Front Maritim de Poblenou y Provençals de Poblenou.

FIGURA 2. MAPA DEL DISTRITO DE SANT MARTÍ POR LOS BARRIOS QUE OBEDECEN A POBLENOU

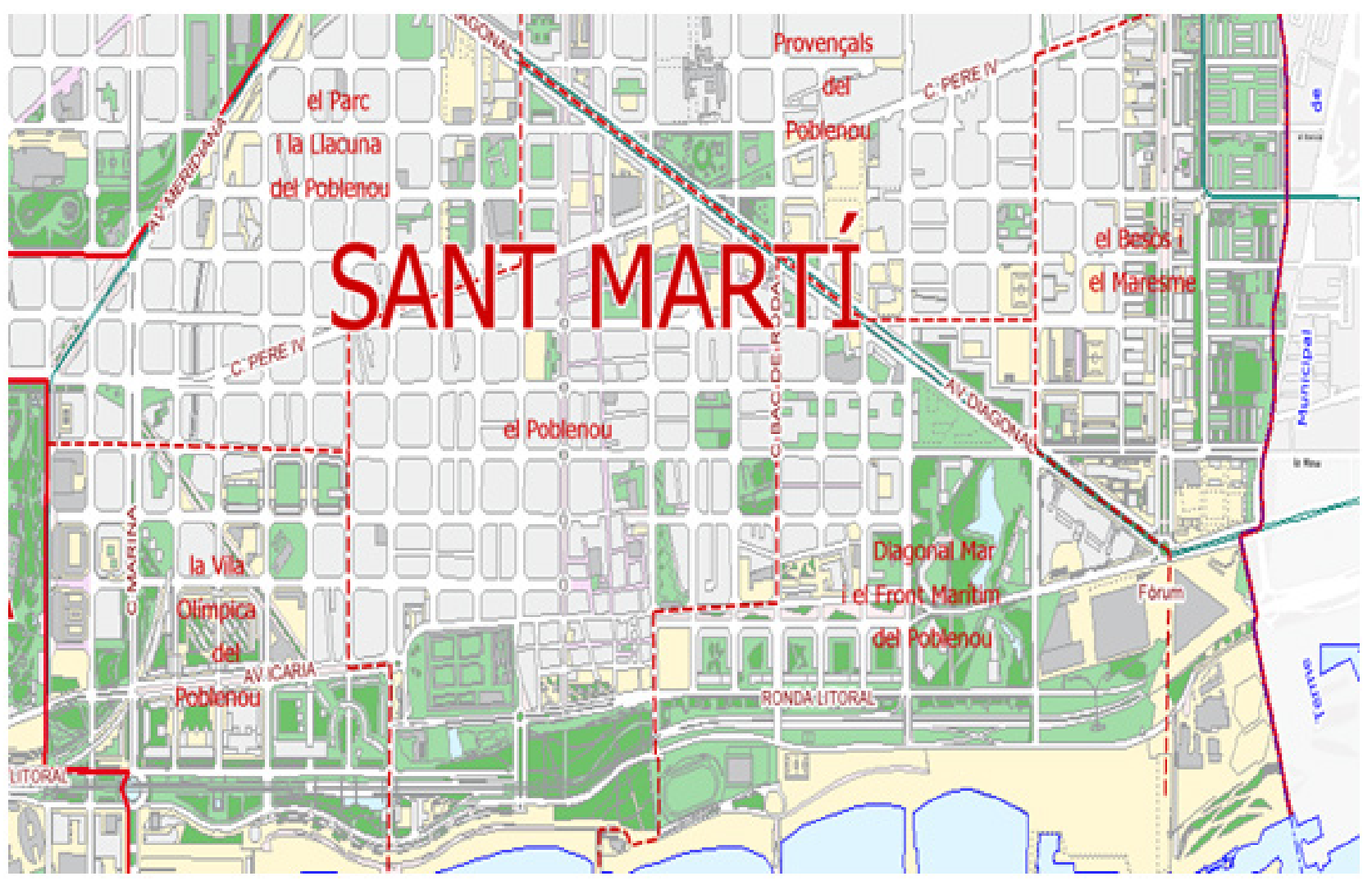

Fuente: Ayuntamiento de Barcelona.

Pese a tener una organización histórica como municipio autónomo, fue integrado en la Ciudad Condal en 1897 y desde el último tercio del siglo XIX se caracterizó por una presencia mayoritaria del entramado industrial y una organización política obrera esencial a escala de todo el Estado (Tatjer y Vilanova, 2002; FAVB, 2008). Tras la Guerra Civil, la reestructuración industrial contó con Poblenou como sede principal del entramado fabril barcelonés, que perduró prácticamente intacto hasta mediada la década de los sesenta, fecha en que comenzó la desindustrialización y la reconversión hacia la terciarización de la producción económica (López y Rodríguez, 2011). En ese momento, Poblenou albergó la larga lista de movimientos vecinales que, a través de la movilización y la actuación cotidiana, encabezaron las reivindicaciones sociales de primera necesidad (la vivienda, el alumbrado, la salubridad, etc.) y pusieron sobre la mesa en el escenario barcelonés, especialmente desde las demandas que hacían públicas los propios barrios de la ciudad.

Casi una década después, comenzó a estructurarse el Plan de Renovación de las Áreas Industriales de Barcelona, implicando una reestructuración de los barrios industriales históricos de la ciudad y, a la postre, la renovación, gentrificación y reestructuración de las centralidades espaciales de dichos espacios

1 http://w110.bcn.cat/portal/site/SantMarti/menuitem.05848ae0b20f8a9a2d852d85a2ef8a0c/?vgnextoid=a6ce4dc8c633a210Vgn VCM10000074fea8c0RCRD\&vgnextchannel=a6ce4dc8c633a210VgnVCM10000074fea8c0RCRD\&lang=es_ES. 
barriales (Casellas y Pallares-Barberá, 2009). De manera simultánea a la desindustrialización, emergieron múltiples movimientos vecinales reivindicando los empleos en las fábricas de Poblenou, así como iniciaron un debate sobre el patrimonio industrial que permanecerá en la agenda política hasta hoy en día (Checa Artasu, 2007, 2008), con un protagonismo determinante en la negociación de los espacios socio-políticos de referencia y en el desarrollo de diferentes proyectos urbanos por parte de las instituciones locales barcelonesas.

Así, tanto los Planes Estratégicos del Sector Cultural de Barcelona de 1999 y 2006, que reconocían el papel esencial de la cultura y la memoria vecinal en los retos globales del espacio urbano, como el Plan de Protección del Patrimonio Industrial de Poblenou y sus modificaciones respectivas del PGM en lo atinente a Poblenou (Ayuntamiento de Barcelona, 2000, 2010a), evidenciaron la consideración institucional de la influencia de los barrios y distritos industriales en la memoria de la ciudad y en la creación de imágenes globales de la misma.

En el caso de Poblenou, ello fue plasmado con la promulgación y ejecución del proyecto 22@. Dicha iniciativa consiste en un proyecto de renovación sectorial y territorial de anteriores fábricas de Poblenou que fue implementado desde el año 2000 con el objetivo de transformar el espacio urbano en clave de ciudad digital y del conocimiento, convirtiendo el mismo en distrito tecnológico que resituase Barcelona globalmente como modelo a exportar (Oliva, 2003; Guillot, 2004; AAVV, 2011). A partir de la configuración de una nueva centralidad en torno a Poblenou, se pretendría cambiar la producción fabril tradicional por otra basada en industrias limpias y vinculadas al sector servicios. Ya en el año 2000 se contemplaba que la reestructuración de las infraestructuras permititiesen la diferenciación zonal y la aglomeración de un clúster empresarial 22@ -principalmente la Fundación Barcelona Digital, Barcelona Media, Biocat, Barcelona Centre Disseny, InMediaTe, Mediatic y Barcelona Design Innovation Cluster (Ayuntamiento de Barcelona, 2009: 13)- modificase la trama anterior configurada alrededor del entramado fabril (artículo 28 del Plan Especial de Infraestructuras de Poblenou, Modificación del Plan General Metropolitano en el ámbito del casco antiguo del Poblenou (Ayuntamiento de Barcelona, 2010b: 18-20).

Según el informe de estado de ejecución del proyecto, se ha renovado el $70 \%$ de las áreas industriales, albergando 7.000 empresas y más de 90.000 trabajadores, de los cuales casi tres cuartas partes se dedican a las denominadas como actividades @ (TIC's, medios de prensa, diseño, tecnologías médicas o energías), frente al 58\% existente en el resto de Cataluña (Ayuntamiento de Barcelona, 2009, 2010a: 3, 2010b: 6, 2012: 54-55; Plan Especial de Protección del Patrimonio Arqueológico, histórico y artístico de la ciudad de BarceIona Districte de Sant Martí, Patrimoni industrial de Poblenou (noviembre de 2006)).

Proceso de transformación que es asumido como macro-proyecto que influirá y modificará no sólo los espacios sobre los que se desarrolla, sino otros ámbitos e incluso los núcleos estructurales de la ciudad. Además, se trata de un cambio inserto en el papel reforzado del planeamiento urbanístico reconocido o de las dinámicas de diferenciación zonal y reestructuración de sectores urbanos en clave de distinción. En cuanto al primer aspecto, el Plan de Equipamientos de Barcelona 2005-2015 consolida el instrumento de planeamiento de forma definitiva en lo que se refiere a la ordenación de los barrios (Ayuntamiento de Barcelona, 2007a: 19-22). Respecto a la diferenciación, zonal, se reconoce como política urbana habitual ya en la Ordenanza sobre Protección del Patrimonio Arquitectónico histórico artístico de la ciudad de Barcelona (aprobado a 18 de enero de 1979); en la Ordenanza sobre el uso de vías y espacios públicos de Barcelona (de 27 de noviembre de 1998); en los artículos 9-10 de la Ordenanza sobre los usos del paisaje urbano en la ciudad de Barcelona (aprobada a 26 de marzo de 1999) o actualmente en el Plan Especial de ordenación de los establecimientos comerciales destinados a la venta de artículos de recuerdos o souvenirs en la ciudad de Barcelona (aprobado en Pleno de 27 de abril de 2008), en sus artículos 10-13.

En términos de localidad, esta reestructuración del espacio urbano se habría aprovechado de cierta obsesión estética o visual por la localidad a partir de lo patrimonial, que tendrá eco a escala global y que, en términos de espacio local, implica una reconstrucción de los imaginarios políticos y de los espacios públicos hacia una nueva estetización del patrimonio industrial. En la línea que apuntaba una artista de la zona:

«Con la reestructuración de los edificios ha pasado un poco como el proceso de Can Ricart... han comprado, industrias limpias, han comprado el espacio de industrias sucias, ha habido una remodelación, (...), de fábricas que se construían con lo que entonces eran los materiales industriales pero que pasado el tiempo se ha convertido en fetiches de la arquitectura, columnas de hierro forjado, piezas, hornos, maquinaria...todo este proceso de estetización que significa borrar toda la lucha política, toda la cuestión de clase y estetizar». 
En efecto, se ha conseguido un vínculo entre la ubicación de industrias de producción limpia ligadas a la calidad de vida y la creación de nuevas zonas verdes o la reurbanización de calles pensando en la peatonalización y el desarrollo del comercio barrial bajo una nueva estética de autenticidad o singularidad (Ayuntamiento de Barcelona, 2009: 5), en una reformulación del espacio local de manera dual. Por un lado, porque esta reestructuración urbana se ha hecho con el objetivo del enriquecimiento con las operaciones urbanísticas recientes - prolongación de Diagonal, Front Maritim, Diagonal-Mar- o con parques de gran dimensión y nuevos ejes urbanos. Por otro, porque se ha dotado de un conjunto de dotaciones y espacios libres que configuran una estructura vertebrada que podría soportar los cambios de usos proyectados, tanto para vivienda como para inversión en producción y tecnología (Ayuntamiento de Barcelona, 2010b: 18-19).

Siguiendo la información empírica analizada, la reestructuración del espacio local poblenoví ha tenido una influencia determinante del ámbito institucional a través de la actuación normativa y del proyecto 22@, tanto en la reestructuración social y urbanística como en términos de discurso e imaginario de cómo se representa e imagina el espacio barrial en clave urbana global. Así, el 22@ ha supuesto una nueva centralidad espacial no sólo en términos de lo que diseña el Ayuntamiento como cartografías de la ciudad digital, sino también en función de las actividades sociales desarrolladas. En cuanto al primer aspecto, se ha generado una segregación territorial favorable a las áreas de tratamiento específico situadas al sur de la Avenida Diagonal, el 22@, el área de Diagonal Mar, el área de Glòries o el área del Fórum-conforme al artículo 7.4 del Plan especial del establecimiento de concurrencia pública de hostelería y otros servicios del distrito de Sant Martí. Estas áreas de tratamiento específico serían las grafiadas en los planos como A y B, esto es, una recreación de la interacción local a través de cartas de navegación trazadas en la normativa. Es decir, un reconocimiento formal de la nueva Barcelona frente a la vieja ciudad. Respecto a la vivencia y reformulación de las actividades sociales, se han producido la reorganización de interacciones en la Rambla, tanto en términos de ocio, turismo y paisaje local, como de producción y organización de socialización política, siendo también esgrimido como argumentos auto-legitimadores, en clave de vincular esa transformación a la memoria histórica local o el patrimonio industrial. A ello se ha terminado de sumar la remodelación de la Diagonal como nuevo límite o frontera urbana en función de la atracción de empresas mutinacionales y de la promoción de iconos arquitectónicos y urbanísticos en clave global.

FIGURA 3. MAPA POR DISTRITOS DEL MUNICIPIO DE MADRID

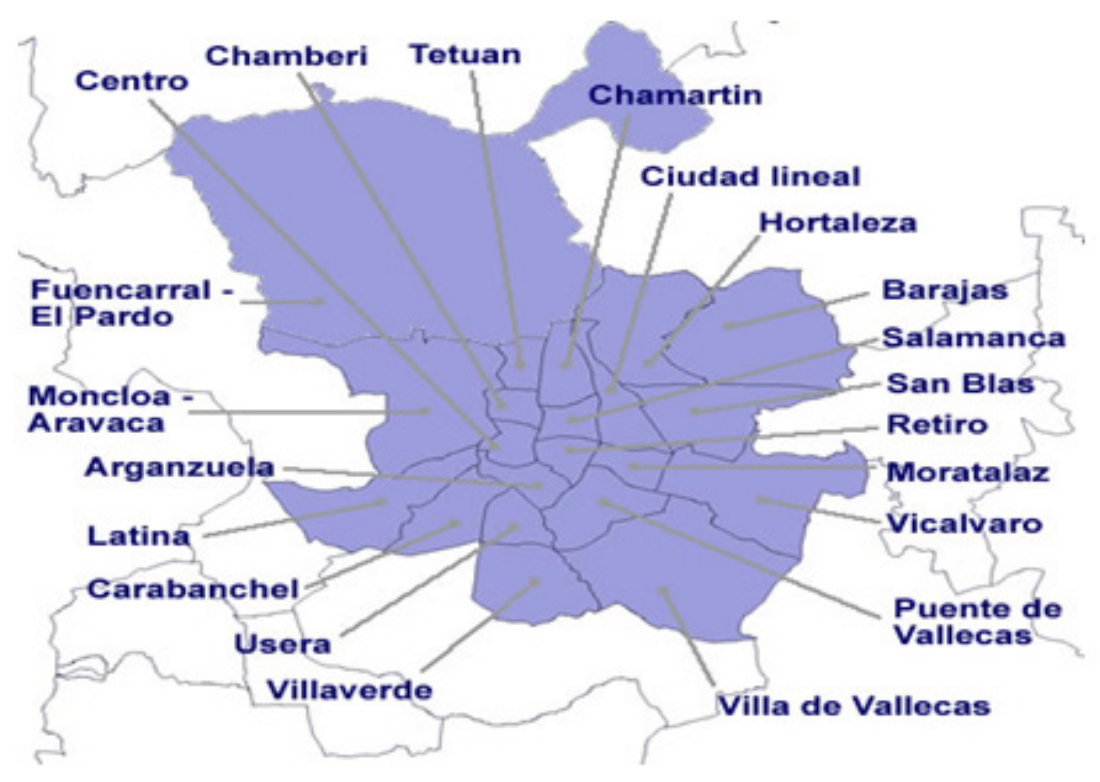

Fuente: Ayuntamiento de Madrid.

Por su parte, Hortaleza es un distrito situado al noreste del municipio de Madrid, colindante con los distritos de Fuencarral-El Pardo, San Blas, Ciudad Lineal, Barajas y el municipio de Alcobendas, que alberga 


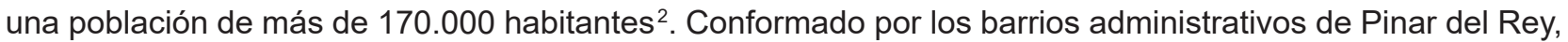
Canillas, Valdefuentes-Valdebebas, Piovera, Palomas y Apóstol Santiago.

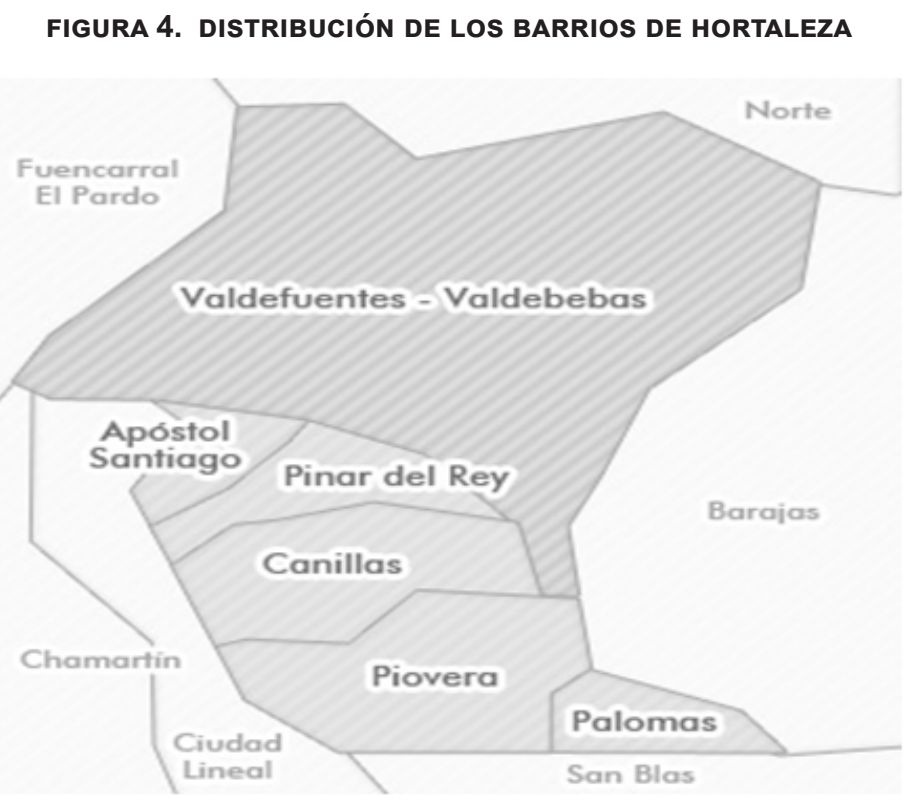

Fuente: www.elidealista.com.

El caso de este distrito es paradigmático en lo que se han considerado procesos de globalización urbana, sobre todo en lo concerniente a dinámicas de filtrado, reestructuración y gentrificación de la ciudad, así como en lo relativo a la producción de representaciones urbanas globales vinculadas a la implantación de actividades de producción de servicios, el ocio, el turismo, el establecimiento de grandes centros comerciales y la ampliación de las redes de transporte urbano.

Si bien ya había sido absorbido por la capital entre 1948-1950 (Martínez Marín, 2000), entre finales de los años 60 y principios de los 70 Hortaleza experimenta una repentina y rápida transformación amparada por su inclusión anterior en el Área Metropolitana de Madrid a partir de 1963 (Otero Carvajal, 2010). En apenas tres años (1967-1970) dobla su población y pasa a convertirse en uno de los núcleos periféricos del área urbana de Madrid con mayor número de habitantes, con más de 103.000 en el año 1971 (Pastor Muñoz, 1986). Mientras en las décadas de los 70 y los 80 , Hortaleza era un distrito con algunas diferencias significativas respecto a la capital, con un carácter residencial y de zona rural dependiente de algunas vías urbanas, especialmente la calle Arturo Soria y la Ciudad Lineal (Martín Roda, 1999), a partir de los años 90 entra de lleno en esa economía de servicios característica de la financierización estatal en su totalidad y de la capital madrileña en los últimos 35 años (López y Rodríguez, 2011). Pese a seguir teniendo un carácter eminentemente residencial y de zona verde, al igual que hace cuarenta años (Pastor Muñoz, 1986; Obispo, 2009; Tienda Burgos et al, 2009), se han producido ciertos cambios sobre la estructura productiva y en el paisaje urbano especialmente vinculados a tres fenómenos: por un lado, la expansión del sector servicios en todo el distrito, fundamentalmente de Centros comerciales y/o grandes superficies, cambiando las formas de estructura productiva y socialización espacial existentes (García Ballesteros, 2001; López de Lucio, 2006; Muñoz del Río, 2010; Ynzenga Acha, 2010). En 1992 tiene lugar la apertura del Centro Comercial Gran Vía de Hortaleza, que se convierte en un nodo fundamental en la configuración de las conexiones con las redes de transporte y comunicación regionales (López de Lucio, 2006), así como en la consolidación de la nueva trama urbana de Hortaleza.

En segundo lugar, se consolida una red extensa de transporte público que comunica Hortaleza con el centro de la ciudad, con las estaciones de ferrocarril de Nuevos Ministerios, Chamartín o Atocha, con el Aero-

2 Disponible en http://www.madrid.org/siesta/RecogidaMapa.icm?codPeticion=29031\&litTabula=Censo de 2011. Personas [consultado a 31 de enero de 2012]. 
GAPP. Nueva Época - N. 20, noviembre 2018 - ISSN: 1989-8991 - DOI: 10.24965/gapp.v0i20.10483 - [Págs. 65-81] Número monográfico - Gobernanza y políticas de desarrollo urbano: teoría y práctica

Gobernanza metropolitana y producción de globalidad en Madrid y Barcelona

Pedro Limón López

puerto Internacional de Madrid-Barajas o con muchas de las zonas adyacentes (Méndez, 2002; De Santiago Rodríguez, 2007; Barrado Timón, 2010).

Relacionado con lo anterior, tiene lugar la construcción de un inmenso Recinto Ferial en el Campo de las Naciones, por un lado, y la apertura del eje urbano de Hortaleza o lo que se conoce como Gran Vía de Hortaleza, por otro, procesos ambos que han tenido un impacto descomunal sobre el paisaje urbano del distrito y sobre las prácticas sociales del mismo, así como consecuencias directas en las formas de movilización política llevadas a cabo. En cuanto al primer elemento, la instalación de los recintos feriales de IFEMA implicó la apertura de diferentes vías de comunicación directa con el Aeropuerto Internacional de Barajas, así como la conexión directa de la trama urbana con el segundo elemento, la Gran Vía de Hortaleza. Ésta, anteriormente conocida como autopista de Cuzco-Barajas (Martín Roda, 1999; Muñoz Carrera, 2011), ha supuesto no sólo la conexión del distrito con el centro urbano, sino la apertura hacia las autopistas M-11, M-12 y M-40, conectando Hortaleza con vías de acceso rápido por automóvil -se produjeron acuerdos entre las administraciones central, local y autonómica conforme al Plan General de ordenación de territorial de 1985, posteriormente reconocido en el artículo 6.a de la Ley 9/2001, de 17 de julio, del Suelo de la Comunidad de Madrid-.

La construcción y consolidación del entramado productivo en torno a la Gran Vía de Hortaleza dio pie tanto a la vinculación interbarrial como al desarrollo creciente de la importancia del distrito en el reconocimiento de las potestades políticas -conforme al Reglamento Orgánico de los distritos de la ciudad de Madrid, ANM 2005/8, de 23 de diciembre de 2004-. Además, la emergencia de un entramado de transporte asociado a la renovación del espacio local hortaleño en clave de pertenencia al área metropolitana madrileña influyeron en las representaciones del propio espacio público de Hortaleza y en relación directa con formas de expansión que trascendían lo local -fuese a través de las autovías, fuese mediante el aeropuerto-.

Finalmente, hay que destacar la construcción del Campo de las Naciones y los Recintos Feriales de IFEMA, que fueron inaugurados en 1991. Esta área se sitúa junto a la M-40 y la autopista M-11 que comunica con el Aeropuerto de Barajas, y en dicho terreno se localizan los pabellones que albergan las ferias anuales celebradas con diferentes temáticas a cargo de IFEMA, el Palacio Municipal de Congresos y el Parque Juan Carlos I (Gea Ortigas, 2002: 55). Estos terrenos, situados entre el norte del distrito y el sur de La Moraleja, se encuentran localizados en una zona altamente rentable en términos inmobiliarios y de disponibilidad de zonas de suelo libre. Además de los pabellones de IFEMA, en esa zona se han construido hoteles, un parque y un campo de golf, así como la aparición de nuevas actividades económicas con la llegada de importantes empresas vinculadas a la industria tecnológica y farmacéutica, junto a una gran transformación en el tipo de vivienda con la construcción de vivienda de alta calidad tanto adosada como exenta (Martín Roda, 1999: 429). Por supuesto, ha tenido lugar una expansión sin precedentes del turismo de ferias y congresos a través de dicha institución, responsable de albergar certámenes internacionales de alcance global, especialmente vinculados al turismo (FITUR), el ocio (EXPO-OCIO), las innovaciones tecnológicas, informáticas y de producción literaria (SIMO, LIBER) o las exposiciones artísticas (ARCO, FERIARTE). De este modo, se ha producido un impulso a la industria terciaria, así como la aparición de espacios de ocio y áreas destinadas a zonas comerciales emergentes, consolidadas a raíz de la instalación de los recintos feriales.

Además de las empresas de intermediación financiera, transporte y comunicaciones o inmobiliarias, hay que recordar la actividad ferial de Madrid, puesto que el IFEMA desarrolla un servicio a la producción entre los que se encuentra su contribución como instrumento de marketing, fuente de información y conocimiento estratégico del sector y su proceso de internacionalización general (Sánchez Moral et al, 2008: 32). Aunque en los años 80 ya existe una alta proporción de firmas transnacionales y presencia especializada de comercio y difusión de estilos de vida o consumo, es el desarrollo del turismo urbano lo que convierte a Madrid en cuarta ciudad europea en turismo en 1998, con más del $70 \%$ de ese turismo fruto de negocios y los congresos (García Escalona, 2000: 214). No en vano, hay quien considera que Madrid se hace global al llegar a superar la renta per cápita media de la media de la Unión Europea, hecho ocurrido en 2007, cuando se llega a los 32.041€ per capita en Madrid (Muñoz Carrera, 2011: 5). Lo cual se consolida si tenemos en cuenta que a lo anterior le sumamos la existencia récord de más de cuatro mil empresas extranjeras y el reconocimiento institucional a nivel normativo con la creación de la Fundación Madrid Ciudad Global, conforme a la instrucción ANM 2008/28, de 24 de julio de 2008.

A todo esto se suma la emergencia del Parque Juan Carlos I como nueva zona verde de alta calidad, de uso público disponible en la zona y con diferentes actividades innovadoras (Gea Ortigas, 2002), que deviene nodo situado entre los distritos de Hortaleza y Barajas y que supone una redefinición de las interacciones y encuentros sociales en términos de espacio público, así como de cara a la percepción de los límites barriales y distritales, así como de una proyección de Hortaleza en clave global. 
Además, el planeamiento vinculado a esta área se incluyó en la vertebración de nuevos modelos de desarrollo territorial alrededor de puntos cardinales en la región metropolitana madrileña -por ejemplo, mediante el desarrollo del Este del Plan General de Madrid de 1997-. Este cambio en los patrones espaciales de Madrid implicó también una transformación de la ordenación socio-espacial de Hortaleza, puesto que se sentó las bases para la planificación y edificación posterior del proyecto Ciudad Aeroportuaria-Parque de Valdebebas -según el acuerdo de 8 de junio de 2011 del Pleno del Ayuntamiento de Madrid, para la modificación del Plan parcial del Suelo urbanizable No. Programado 4.01 Ciudad Aeroportuaria-Parque de Valdebebas-, además de consolidarse una reestructuración del espacio local en clave global desde las propias instituciones municipales.

En efecto, el Ayuntamiento de Madrid promulgó la Orden de 4 de abril de 2011, de la Consejería de Economía y Hacienda, por la que se declara zona de gran afluencia turística al área denominada Recintos Feriales-Campo de las Naciones y los edificios ubicados en las aceras colindantes a la misma de la ciudad de Madrid. Más allá de la influencia que haya tenido en la expansión de las diferentes actividades económicas y residenciales, hay que tener en cuenta dos cosas. En primer lugar, esta Orden implicó la reestructuración de las actividades económicas del distrito hortaleño de acuerdo al impacto generado por los Recintos Feriales, especialmente aquellas desarrolladas a lo largo de la Gran Vía de Hortaleza y de la carretera de Canillas (alrededor del Dreams Palacio de Hielo). En términos de actividades productivas, la consideración de los Recintos Feriales y los edificios próximos como «zona de gran afluencia turística» implicó la calificación de áreas turísticas de forma progresiva para la Gran Vía de Hortaleza y para los imaginarios espaciales significados en la producción de globalidad de Hortaleza, especialmente las tramas gentrificadas y nuevos espacios de ocio, comercio y producción visual. Es decir, de cara a la atracción de inversión, empleo, actividades o construcción de infraestructuras económicas, Hortaleza en tanto que lugar de emplazamiento y proyección de actividades económicas quedó vinculado al turismo y a las ferias comerciales a través (y a partir) de IFEMA. En segundo lugar, este reconocimiento se hace atendiendo no sólo a las actividades en sí mismas (por ser de interés turístico), sino con arreglo a las proyecciones que emanan de las mismas y hacia donde pueden dirigirse, en este caso al contexto internacional y posteriormente en función de necesidades globales. Así, la Ley 15/1997, de 25 de junio, de ordenación de actividades feriales de la Comunidad de Madrid, ya recogía la evolución del contexto económico internacional, así como la importancia de las ferias y exposiciones en ese impacto internacional (preámbulo). En este sentido, el artículo 22 reconoce la potestad a la CAM de promocionar las actividades feriales en interés de la región más allá de sus territorios. Cuestión que fue culminada en la Orden de 2011, al proclamar no sólo la consolidación de la ciudad de Madrid «como destino turístico preferente a nivel nacional e internacional, convirtiendo al turismo en un motor principal de actividad económica», sino estableciendo un nexo inextricable entre la proyección global de Madrid a través del turismo de ferias y congresos, los Recintos Feriales de IFEMA y la reestructuración urbana de Hortaleza en su conjunto.

\section{DISCUSIÓN: PRODUCCIÓN DE GLOBALIDAD DESDE POBLENOU Y HORTALEZA}

A lo largo de este artículo, se ha probado la pertinencia del uso del concepto de producción de globalidad en el análisis de procesos de gentrificación urbana en los casos de Hortaleza en Madrid y Poblenou en Barcelona. Además, resulta pertinente afirmar que en ambos casos, desde la perspectiva de la Geografía Política del Derecho, existen indicios de que estas dinámicas de gentrificación se han erigdo en elementos centrales de la producción de globalidad madrileña y barcelonesa. En efecto, existe una relación visible, aunque distinta en función del caso, entre la actuación institucional desarrollada y mantenida en Poblenou y Hortaleza, y la producción de globalidad consolidada a través de los fenómenos de gentrificación de ambos lugares, en los que el reconocimiento institucional y la producción política normativa han sido centrales en términos históricos y aplicados. Considerando la imaginación geográfica como «la sensibilidad hacia la importancia del Lugar, el espacio y el paisaje en la formación y conducta de la vida social (...)» (Johnston et al, 2000: 321), el análisis empírico permite aventurar que la actuación de los gobiernos municipales en Madrid y Barcelona, así como las colaboraciones con las instuciones autonómicas y centrales, han implicado una transformación de la imaginación geográfica de ambos lugares a partir de los fenómenos de gentrificación que, simultáneamente, han transformado los imaginarios de la escala de proyección barrial, deviniendo global y globalizante de la propia ciudad.

No obstante, los mecanismos y formas en que esto se ha llevado a cabo difiere, atendiendo a las particularidades de cada caso y a la actuación desplegada en cada lugar. 
GAPP. Nueva Época - N. 20, noviembre 2018 - ISSN: 1989-8991 - DOI: 10.24965/gapp.v0i20.10483 - [Págs. 65-81] Número monográfico - Gobernanza y políticas de desarrollo urbano: teoría y práctica

Gobernanza metropolitana y producción de globalidad en Madrid y Barcelona

Pedro Limón López

Así, el reconocimiento del patrimonio industrial de Poblenou como uno de los ejes culturales de Barcelona se construyó desde la óptica del barrio, no desde la óptica nuclear de la ciudad, significando que toda la renovación económica que pudiera articularse en la zona tendría que hacerse teniendo en cuenta, al menos parcialmente, el espacio barrial en su conjunto. Al convertirse en símbolo de la renovación y del cambio económico urbano, Poblenou (en la forma del 22@ ligado a las economías creativas) se transformó en una imagen esencial en la producción de globalidad barcelonesa a partir de su singularidad como ámbito de producción, que era lo que se reconocía, entre otras cosas, con la promulgación del Plan de protección patrimonial de Poblenou. Así, además de la centralidad en la recreación de espacios vinculados a la producción creativa, artística y de nuevos espacios de consumo relacionados con la reestructuración de Poblenou, reconocidas en múltiples estudios (Pareja Eastway y Pradel i Miquel, 2010; Martí-Costa y Pradel i Miquel, 2012), el presente trabajo añade la importancia de la reformulación legal y normativa a través de la actuación institucional en ese rediseño del espacio cotidiano como símbolo de producción de globalidad urbana.

Por su parte, en el caso de Hortaleza no existió tal reconocimiento espacial como eje nuclear ni del patrimonio ni de algo que pudiera parecerse a una cultura madrileña, entre otras cosas por las diferencias existentes entre Madrid y Barcelona de cara a la producción de imágenes globales o de las políticas públicas de promoción urbana. En el caso barcelonés, los Juegos Olímpicos sirvieron como punto de partida de la renovación urbana, tanto en la modificación de la trama de la ciudad como en la atracción de flujos turísticos, mientras que en el caso madrileño, la consolidación de su principal agente productor global, como es IFEMA, ha tenido lugar no a partir de acontecimientos de alcance internacional, sino del desarrollo progresivo de pequeños eventos feriales y de congresos de alcance mundial que, a su vez, han ido dando pie a eventos más amplios como inicio de una suerte de patrimonio cultural madrileño (Martín Roda, 1999; Barrado Timón, 2010). Además, mientras que el patrimonio industrial se convirtió en un imaginario global de la cultura barcelonesa, la ruralidad y el carácter residencial hortaleño apenas sirvieron para articular una importante transformación urbana del área y de todo el distrito, porque lo que realmente actúa como productor de globalidad es otro ámbito, como IFEMA.

Finalmente, hay que señalar dos matices referidos al enfoque adoptado en este trabajo: en primer lugar, la Geografía política del Derecho considera de forma preeminente la actuación institucional en los procesos aquí analizados, lo cual es una ventaja en términos de recolección de material empírico, pero resta protagonismo a otros agentes sociales, como los movimientos vecinales o la estructura empresarial. En segundo lugar, precisamente por el carácter de proceso de la producción de globalidad, sería pertinente incluir en futuros trabajos dichos mecanismos por los cuales se producen actividades productivas de índole global, así como representaciones globalizantes de la ciudad, si bien considerando la actuación institucional analizada como factor central del cambio social y político urbano en Madrid y Barcelona.

\section{REFERENCIAS BIBLIOGRÁFICAS}

AA.VV (2004): La otra cara del Fòrum de les Cultures, S. A. Barcelona: Bellaterra.

AA.VV (2007a): Hortaleza: pasado y presente de un distrito.

AA.VV (2007b): M07. Memoria 2007 Districte de Sant Martí. Barcelona: Ajuntament de Barcelona-Districte de Sant Martí.

AA.VV (2011): "Economía del conocimiento y del territorio" [Dossier], Revista Econòmica de Catalunya, 64, octubre de 2011.

AGNEW, J. (2005): Geopolítica: una re-visión de la política mundial. Madrid: Trama.

AGUILERA, G. (2013): "Barris dividits per la butxaca", en Carrer, núm. 127, pág. 24, febrero 2013.

AYUNTAMIENTO DE BARCELONA (2000): Plan Especial de Infraestructuras de Poblenou.

AYUNTAMIENTO DE BARCELONA (2005): Estado de ejecución del 22@ en torno a la Modificación del plan general metropolitano en el ámbito del casco antiguo de Poblenou, distrito de Sant Martí.

AYUNTAMIENTO DE BARCELONA (2006): Plan Estratégico de Cultura de Barcelona. Nuevos Acentos 2006, Barcelona: Altés.

AYUNTAMIENTO DE BARCELONA (2007a): Plan de equipamientos de Barcelona 2005-2015, Barcelona.

AYUNTAMIENTO DE BARCELONA (2007b): Plan de equipamientos de Barcelona 2005-2015, Barcelona.

AYUNTAMIENTO DE BARCELONA (2008): Estado de ejecución del 22@ en torno a la Modificación del plan general metropolitano en el ámbito del casco antiguo de Poblenou, distrito de Sant Martí.

AYUNTAMIENTO DE BARCELONA (2009): Estado de ejecución del 22@ en torno a la Modificación del plan general metropolitano en el ámbito del casco antiguo de Poblenou, distrito de Sant Martí, diciembre de 2009.

AYUNTAMIENTO DE BARCELONA (2010a): Estado de ejecución del 22@ en torno a la Modificación del plan general metropolitano en el ámbito del casco antiguo de Poblenou, distrito de Sant Martí. 
GAPP. Nueva Época - N. 20, noviembre 2018 - ISSN: 1989-8991 - DOI: 10.24965/gapp.v0i20.10483 - [Págs. 65-81] Número monográfico - Gobernanza y políticas de desarrollo urbano: teoría y práctica

Gobernanza metropolitana y producción de globalidad en Madrid y Barcelona

Pedro Limón López

AYUNTAMIENTO DE BARCELONA (2012a): Estado de ejecución del 22@ en torno a la Modificación del plan general metropolitano en el ámbito del casco antiguo de Poblenou, distrito de Sant Martí.

AYUNTAMIENTO DE BARCELONA (2012b): Memoria del Distrito de Sant Martí.

AYUNTAMIENTO DE MADRID (2012a): Hacia el Plan Estratégico de Cultura del Ayuntamiento de Madrid (2012-2015), Madrid.

AYUNTAMIENTO DE MADRID (2012b): Informe distrital Hortaleza.

AYUNTAMIENTO DE MADRID (2007): Resumen Ejecutivo Estrategia de Posicionamiento Internacional, Oficina de Estrategia y Acción Internacional "Madrid Global".

BARRADO TIMÓN, D. (2010): "Gran ciudad y turismo en la transición postindustrial: nuevos y viejos procesos, nuevas y viejas teorías. El ejemplo del área metropolitana de Madrid”, en Scripta Nova. Revista Electrónica de Geografía y Ciencias Sociales. Universidad de Barcelona, vol. 14, núm. 314, págs. 310-322, 10 de marzo de 2010.

BLANCO, I. y SUBIRATS, J. (2012): "Políticas urbanas en España: dinámicas de transformación y retos ante la crisis", en Geopolítica(s). Revista de Estudios de Espacio y poder, vol. 3, núm. 1, págs. 15-33, enero-junio 2012.

BLANCO, I.; BONET, J. y WALLISER, A. (2011): "Urban governance and regeneration policies in historic city centres: Madrid and Barcelona", en Urban Research and Practice, vol. 4, núm. 3, págs. 326-343. DOI: https://doi.org/10.10 80/17535069.2011.616749.

BLOMLEY, N. (2003): "Law, property and the spaces of violence", en Annals of the Association of American Geographers, vol. 93, núm. 1, págs. 121-141.

BLOMLEY, N. (2004): “Un-real estate: proprietary space and public gardening”, en Antipode, vol. 36, núm. 4, págs. 614-641. DOI: https://doi.org/10.1111/j.1467-8330.2004.00440.x.

BLOMLEY, N. (2008): "Making space for law", en COX, K.; LOW, M.; y ROBINSON, J. The Sage Handbook of political geography, 155-168. London-Thousand Oaks-New Delhi: Sage. https://doi.org/10.4135/9781848607880.n10.

BORJA, J. (2005): La ciudad conquistada. Madrid: Alianza.

BURAWOY, M. (1991): Ethnography unbound. Power and resistance in the modern metropolis. Berkeley-Oxford: University of California Press. DOI: https://doi.org/10.2307/2580054.

CASELLAS, A. y PALLARES-BARBERA, M. (2009): "Public-sector intervention in embodying the new economy in inner urban reas: the Barcelona experience”, en Urban Studies, vol. 46, núm. 5/6, págs. 1.137-1.155, mayo 2009.

CHECA ARTASU, M. M. (2007): "Geografías para el patrimonio industrial en España: el caso de Barcelona", en Scripta Nova, Revista electrónica de Geografía y Ciencias Sociales, Universidad de Barcelona, vol. XI, núm. 245 (32), 1 de agosto de 2007. DOI: $h$ ttp://dx.doi.org/10.1344/sn2007.11.1359.

CHECA ARTASU, M. M. (2008): "Una herramienta para la planificación urbana: la documentación del patrimonio. El caso de Barcelona (España)", en Scripta Nova, Revista electrónica de Geografía y Ciencias Sociales, vol. XII, núm. 270 (141), 1 de agosto de 2008. DOI: http://dx.doi.org/10.1344/sn2008.12.1565.

CHOULIARAKI, L. y FAIRCLOUGH, N. (1999): Discourse in Late Modernity: Rethinking critical discourse analysis. Edinburgh: Edinburgh University Press. DOI: https://doi.org/10.1177/00754240122005305.

COASE, R. (1960): "The problem of social cost", en The Journal of Law and Economics (octubre 1960), núm. 1, págs.1-44. DOI: $h$ ttps://doi.org/10.1086/674872.

DANGSCHAT, J. S. (2009): "Space matters. Marginalization and its places", en International Journal of Urban and Regional Research, vol. 33, núm. 3, págs. 835-840, September 2009. DOI: https://doi.org/10.1111/j.14682427.2009.00924.x.

DE SANTIAGO RODRÍGUEZ, E. (2007): "Madrid, «ciudad única». Pautas y lógicas espaciales recientes en la región madrileña: las grandes transformaciones estructurales; el despliegue del nuevo «paradigma único» en la región urbana de Madrid", en Urban, vol. 1, núm. 12, págs. 8-33.

DENZIN, N. y LINCOLN, Y. (2005): The Sage Handbook of qualitative research. London-Thousand Oaks-New Delhi: SAGE.

DOT JUTGLA, E.; CASELLAS, A.; PALLARĖS-BARBERÀ, M. (2010): "Gentrificación productiva en Barcelona: efectos del nuevo espacios económico", en Actas de las IV Jornadas de Geografía Económica, Grupo de Geografía Económica de la Asociación de Geógrafos Españoles, León, 1 y 2 de julio de 2010, págs. 1-13.

FAINSTEIN, S. S.; HOFFMANN, L. M.; y JUDD, D. R. (2003): "Making theoretical sense of tourism", en HOFFMAN, L. M.; FAINSTEIN, S. S.; y JUDD, D. R. (eds.) (2003), Cities and visitors. Regulating people, markets, and city space: 239-253. Malden-Oxford-Carlton: Blackwell. DOI: https://doi.org/10.1002/9780470773673.ch13.

FAVB (2008): "La Barcelona dels barris", en Quaderns de Carrer, núm. 3, maig 2008. Barcelona: FAVB.

FAVB (2010): “1970-2010. 40 anys d'acció veïnal”, en Colleció Quaderns de Carrer, núm. 5, maig 2010. Barcelona: FAVB.

FAVB (2011): "Desnonaments, indignació i ocupació", en Carrer, núm. 120.

FAVB (2013): "Barri ric, barri pobre", en Carrer, núm. 127, febrero 2013.

FOREST, B. (2001): "Mapping democracy: racial identity and the quandary of political representation", en Annals of the Association of American Geographers, vol. 91, núm. 1, págs. 143-166. DOI: https://doi.org/10.1111/00045608.00237.

GARCÍA BALLESTEROS, A. (2001): "Las motivaciones hacia el uso de los centros comerciales en Madrid”, en Anales de Geografía de la Universidad Complutense, núm. 21, págs. 257-284.

GARCÍA ESCALONA, E. (2000): "El debate de Madrid ciudad global: mito y realidad", en Madrid: Revista de Arte, Geografía e Historia, núm. 3, págs. 203-230. 
GAPP. Nueva Época - N. ${ }^{\circ}$ 20, noviembre 2018 - ISSN: 1989-8991 - DOI: 10.24965/gapp.v0i20.10483 - [Págs. 65-81] Número monográfico - Gobernanza y políticas de desarrollo urbano: teoría y práctica

Gobernanza metropolitana y producción de globalidad en Madrid y Barcelona

Pedro Limón López

GEA ORTIGAS, M. I. (2002): Hortaleza y Barajas: historia de los distritos de Madrid. Madrid: La Librería.

GIL DE ARRIBA, C. (2010): "Capitales culturales europeas. El concepto europeo de cultura en relación con algunos procesos actuales de renovación simbólica y de transformación urbana”, en Scripta Nova. Revista Electrónica de Geografía y Ciencias Sociales, vol. XIV, núm. 339, 20 de octubre de 2010.

GUILLOT, S. (2004): El proyecto 22@Barcelona. Estado de ejecución y estudio comparativo con experiencias similares en Europa. Barcelona: Aula Barcelona, diciembre 2004.

HALL, P. (1984): The world cities. London: Weidenfeld and Nicolson. DOI: https://doi.org/10.1016/0264-2751(96)90037-2.

HALL, P. y PAIN, K. (2006): The polycentric metropolis: learning from mega-city regions in Europe. London: SterlingVA: Earthscan.

HARVEY, D. (2007): Espacios del capital. Madrid: Akal.

HERBERT, S. (2010): “Contemporary geographies of exclusion III: to assist or punish?", en Progress in Human Geography, vol. 35, núm. 2, págs. 256-263.

JOHNSTON, R. J.; GREGORY, D. y SMITH, D. M. (2000): Diccionario Akal de Geografía Humana. Madrid: Akal.

JUDGE, D.; STOKER, G. y WOLMAN, H. (eds.) (1998): Theories of urban politics. Londres: SAGE.

LEES, L.; SLATER, T. and WYLY, E. (2008): Gentrification. New York-Milton Park: Routledge.

LINDÓN, A. (2007): "La ciudad y la vida urbana a través de los imaginarios urbanos", en Revista EURE, vol. 33, núm. 99, págs. 7-16.

LÓPEZ DE LUCIO, R. (2006): “Espacio público e implantación comercial en la Comunidad de Madrid”, en Cuadernos de investigación urbanística, vol. 1, núm. 23, págs. 1-53.

LÓPEZ, I. y RODRÍGUEZ, E. (2011): “El modelo español”, en New Left Review, núm. 69, págs. 5-26.

MARCUSE, P. y VAN KEMPEN, R. (2000): Globalizing cities. A new spatial order? Oxford-Malden: Routledge.

MARTÍ-COSTA, M. y PRADEL I MIQUEL, M. (2012): "The knowledge city against urban creativity? Artists' workshops and urban regeneration in Barcelona", en European Urban and Regional Studies, vol. 19, núm. 1, págs. 92-108.

MARTIN, D.; SCHERR, A. W. y CITY, C. (2010): "Making law, making place: lawyers and the production of space", en Progress in Human Geography, vol. 34, núm. 2, págs. 175-192. DOI: https://doi.org/10.1177/0309132509337281.

MARTÍN RODA, E. M. (1999): "Hortaleza: la articulación del espacio en un distrito de la periferia madrileña”, en Madrid: Revista de Arte, Geografía e Historia, núm. 2, págs. 421-438.

MARTÍNEZ MARÍN, J. A. (2000): "Madrid, de Villa a Metrópoli. Las transformaciones del siglo XX", en Cuadernos de Historia Contemporánea, núm. 22, págs. 225-249.

MÉNDEZ, R. (2002): “¿Del industrioso Madrid al Madrid post-industrial? En torno a dos siglos de industrialización urbana”, en Anales de Geografía de la Universidad Complutense, vol. extraordinario, págs. 337-347.

MITCHELL, D. (2007): "Muerte entre la abundancia: Ios paisajes como sistemas de reproducción social”, en NOGUÉ, J. (ed.) (2007), La construcción social del paisaje, págs. 85-110. Madrid: Biblioteca Nueva, Colección Teoría y Paisaje.

MITCHELL, D. y HEYNEN, N. (2009): "The geography of survival and the right to the city: speculations on surveillance, legal innovation and the criminalization of intervention", en Urban Geography, vol. 30, núm. 6, págs. 611-632. DOI: $h$ ttps://doi.org/10.2747/0272-3638.30.6.611.

MITCHELL, D. y STAEHELI, L. (2005): "Permitting protest: parsing the fine geography of dissident in America", en International Journal of Urban and Regional Research, vol. 29, núm. 4, págs. 796-813, diciembre de 2005.

MUÑOZ CARRERA, Ó. (2011): "Gentrificación y reestructuración del espacio social en Madrid”, Madrid: Observatorio Metropolitano, págs. 1-31 (disponible en http://www.observatoriometropolitano.org/wp-content/uploadsobservatorio/2011/03/GENTRIFICACI\%C3\%93N-Y-REESTRUCTURACI\%C3\%93N-DEL-ESPACIO-SOCIAL-ENMADRID.pdf.

MUÑOZ DEL RÍO, L. (2010): "Implicaciones sociales y urbanas de las recientes transformaciones de la estructura comercial en los centros históricos. El caso de la centralidad madrileña”, incluido en el Primer bloque La ciudad como ecosistema urbano, del Congreso Ciudad, territorio y paisaje: una mirada multidisciplinar, en el Centro de Ciencias Históricas y Sociales del CSIC, en Madrid del 5 al 7 de mayo de 2010.

MUÑOZ, F. (2008): UrBANALización: paisajes comunes, lugares globales. Barcelona: Gustavo Gili. DOI: https://doi. org/10.5565/rev/enrahonar.234.

MUÑOZ, F. (2010): "Contra la urbanalització: de la ciudad post-it a la ciutat pòsit", en Revista del Centre d'Estudis Jordi Pujol, núm. 12, págs. 189-200.

NAVARRO YÁÑEZ, C. J. (2013): "Do creatives cities have a dark side? Cultural scenes and socioeconomic status in Barcelona and Madrid (1991-2001)", en Cities, núm. 35, págs. 213-220.

OBISPO, A. (2009): Más de cien años de historia de Hortaleza. Madrid: Ediciones La librería.

OBSERVATORIO ECONÓMICO (2005): Reequilibrio territorial en la Ciudad de Madrid. Madrid: Ayuntamiento de Madrid.

OBSERVATORIO ECONÓMICO (2011): Futuro Ciudad Madrid 2020. Madrid: Ayuntamiento de Madrid.

OLIVA, A. (2003): El districte d'activitats 22@bcn. Barcelona: Aula Barcelona-Publicacions de la Universitat de Barcelona.

OTERO CARVAJAL, L. E. (2010): "Madrid, de capital a metrópoli”, en PRIEGO, C. (ed.), Sociedad y espacio urbano de Madrid en el siglo xx. Ciclo de Conferencias Madrid, 17-19 de febrero, págs. 10-33. 
GAPP. Nueva Época - N. 20, noviembre 2018 - ISSN: 1989-8991 - DOI: 10.24965/gapp.v0i20.10483 - [Págs. 65-81] Número monográfico - Gobernanza y políticas de desarrollo urbano: teoría y práctica

Gobernanza metropolitana y producción de globalidad en Madrid y Barcelona

Pedro Limón López

PAINTER, J. (1998): "Regulation theory and postfordism", en STOKER, G. y WOLMAN, H. (eds.) Theories of Urban politics, págs. 269-284. London: SAGE.

PAREJA EASTWAY, M.; TURMO GARUZ, J.; GARCÍA FERRANDO, L.; y PRADEL I MIQUEL, M. (2009): The magnetism of Barcelona. The view of transnational migrants, Amsterdam: University of Amsterdam, ACRE Report 7.2.

PAREJA-EASTWAY, M. y PRADEL, M. (2010): "New economy, new governance approaches? Fostering creativity and knowledge in the Barcelona Metropolitan Region", en Creatives Industries Journal, vol. 3, núm. 1, págs. 29-46.

PASTOR MUÑOZ, F. J. (1986): Historia del distrito de Hortaleza. Madrid: Ayuntamiento, Concejalía de Relaciones Institucionales y Comunicaciones.

RAGIN, CH. y BECKER, H. (1992): What is a case? New York-Melbourne: Cambridge Universtity Press.

RECIO, A. (2013): “Com mesurem la desigualtat", en FAVB (2013) "Barri ric, barri pobre”, en Carrer, núm. 127, 19 febrero 2013.

SÁNCHEZ MORAL, S.; CALATRAVA ANDRÉS, A. y MELERO GUILLÓ, A. (2008): "Las funciones comando de Madrid en la economía global: una aproximación a través del proceso de atracción de capital extranjero", en Revista EURE, vol. 34, núm. 101, págs. 25-44. DOI: https://doi.org/10.4067/s0250-71612008000100002.

SMITH, N. (1996): The new urban frontier: gentrification and the revanchist city. London: Routledge. DOI: https://doi. org/10.2307/2137563.

SMITH, N. (2008): "Gentrificación generalizada: de la anomalía local a la regeneración urbana", en Ciudades en reconstrucción: necesidades sociales, transformación y mejora de barrios, págs. 31-48. Barcelona: TerritoriosDiputació de Barcelona.

STAKE, R. E. (1998): Investigación con estudio de casos. Madrid: Ediciones Morata.

STAEHELI, L. A. (2010): "Political geography: democracy and the disorderly public", en Progress in human geography, vol. 34, núm. 1, págs. 67-78. DOI: https://doi.org/10.1177/0309132509105006.

TATJER, M. M. y VILANOVA, A. (2002): La ciutat de les fabriques: itineraries industrials de Sant Martí. Barcelona: Districte de Sant Martí.

TIENDA BURGOS, T.; ANULA FERNÁNDEZ, R.; y PEREYRA, D. (2009): "Aquí y ahora: Hortaleza. Crónica de un barrio indómito y sus desafíos al PP”, en Viento Sur, núm. 102, págs. 115-118.

VAN AALST, I. y VAN MELIK, R. (2012): "City festivals and urban development: does place matter?", en European Urban and Regional Studies, vol. 19, núm. 2, págs. 195-206, April 2012.

YNZENGA ACHA, B. (2010): "Mega barrios: la oportunidad perdida", en PRIEGO, C. (ed.) Sociedad y espacio urbano de Madrid en el siglo XX. Ciclo de Conferencias Madrid, 17-19 de febrero, págs. 34-49. Madrid: Museo de Historia de Madrid.

ZÁRATE MARTÍN, M. T. y RUBIO BENITO, M. Á. (2010): Conceptos y prácticas en Geografía Humana. Madrid: Centro de Estudios Ramón Areces. 